\title{
Understanding Health Care Costs in a Wisconsin Acute Leukemia Population
}

Patricia Steinert Ron A. Cisler

Follow this and additional works at: https://aah.org/jpcrr

Part of the Health Services Research Commons

\section{Recommended Citation}

Steinert P, Cisler RA. Understanding health care costs in a Wisconsin acute leukemia population. J Patient Cent Res Rev. 2016;3:142-9. doi: 10.17294/2330-0698.1261

Published quarterly by Midwest-based health system Advocate Aurora Health and indexed in PubMed Central, the Journal of Patient-Centered Research and Reviews (JPCRR) is an open access, peer-reviewed medical journal focused on disseminating scholarly works devoted to improving patient-centered care practices, health outcomes, and the patient experience. 


\title{
Understanding Health Care Costs in a Wisconsin Acute Leukemia Population
}

\author{
Patricia Steinert, PhD, MBA, ${ }^{1,3}$ Ron A. Cisler, PhD, MS ${ }^{1,2,4}$ \\ ${ }^{1}$ University of Wisconsin-Milwaukee, Milwaukee, WI \\ ${ }^{2}$ Center for Urban Population Health, Milwaukee, WI \\ ${ }^{3}$ Medical College of Wisconsin, Milwaukee, WI \\ ${ }^{4}$ University of Wisconsin-Madison School of Medicine and Public Health, Madison, WI
}

\begin{abstract}
Purpose We investigated factors driving health care costs of patients with a diagnosis of acute myeloid and acute lymphoblastic leukemia.

Methods Standard costs identified in insurance claims data obtained from the Wisconsin Health Information Organization were used in a sample of 837 acute leukemia patients from April 2009 to June 2011. The Andersen behavioral model of health care utilization guided selection of patient and community factors expected to influence health care costs. A generalized linear model fitting gamma-distributed data with log-link technique was used to analyze cost.

Results $\quad$ Type of treatment received and disease severity represented significant cost drivers, and patients receiving at least some of their treatment from academic medical centers experienced higher costs. Inpatient care and pharmacy costs of patients who received treatment from providers located in areas of higher poverty experienced lower costs, raising questions of potential treatment and medical practice disparities between provider locations. Directions of study findings were not consistent between different types of services received and underscore the complexity of investigating health care cost.

Conclusions While prevalence of acute leukemia in the United States is low compared to other diseases, its extreme high cost of treatment is not well understood and potentially influences treatment decisions. Acute leukemia health care costs may not follow expected patterns; further exploration of the relationship between cost and the treatment decision, and potential treatment disparities between providers in different socioeconomic locations, is needed. (J Patient Cent Res Rev. 2016;3:142-149.)
\end{abstract}

Keywords health care costs; acute leukemia cost; administrative data use

As the United States health care system works to control health care costs, it becomes increasingly important to understand the factors associated with high-cost care. ${ }^{1}$ Exploring cost factors of low-prevalence but highcost cancers is important to both identify and better understand underlying health care utilization patterns and cost. In 2007, Yu found the use of prolonged hospital care, high levels of medical technology and specialized health care services resulted in a high cost of treatment. ${ }^{2}$ To achieve long-term survival, patients

Correspondence: Patricia Steinert, PhD, MBA, 9200 W. Wisconsin Avenue, Milwaukee, WI, 53226, T: 414-805-0648, F: 414-805-0714,

Email: psteinert@mcw.edu diagnosed with acute leukemia are expected to utilize diverse health care services.

Prior models of health care utilization have identified patient and community factors as determinants in the use of services. ${ }^{3-5}$ Specifically, the Andersen behavioral model proposes that an individual's health care use can be attributed to individual and community or organizational factors that will either increase or decrease utilization. ${ }^{4}$ Utilization factors are associated with biology (such as age and gender), social structure (such as education, occupation, ethnicity, environment and culture), and health beliefs (such as attitudes, values and knowledge). Furthermore, the availability of individual and community resources like income, insurance, transportation and diversity of services 
offered drive the use of health care. Finally, utilization may be influenced by the individual's perceived or evaluated need for these services as well as his or her ability to access health care resources, work within the health care system and effectively manage the clinical problem. Understanding cost factors of uncommon, high-cost cancers is important to patients, providers and communities impacted by these diseases.

This study investigated patient and community variables that may influence the cost of treatment for patients in Wisconsin diagnoses with acute myeloid leukemia or acute lymphoblastic leukemia. More specifically, this study sought to identify factors that may influence higher cost treatment of these two diseases.

\section{METHODS}

\section{Data Source and Study Population}

This study received approval from the University of Wisconsin-Milwaukee Institutional Review Board. Insurance claims data obtained from the Wisconsin Health Information Organization (WHIO) Datamart were used to identify a study population of 837 acute leukemia patients treated with chemotherapy alone or chemotherapy and hematopoietic stem cell transplant (HCT) from April 2009 to June 2011. WHIO is a statewide collaboration of insurance companies, health care providers, large employers and public agencies. Starting in 2005, this group developed a state-level database of health insurance claims in order to provide data useful for examining health care issues related to quality, efficiency and safety within the state of Wisconsin. ${ }^{6}$ Access to the data is available through the WHIO Health Analytics Exchange, a database reporting system covering more than 247.6 million insurance claims for care to roughly 3.8 million Wisconsin residents. The exchange began collecting data in 2008 and provides access to a rolling 27 months of data, a total of 23.1 million episodes of care. Version 6 of the WHIO Datamart contains information for approximately $64.9 \%$ of Wisconsin's population. Commercial claims represent $42 \%$ of the total, $25 \%$ are Medicaid Fee-For-Service claims, 20\% are Medicaid HMO claims, and $13 \%$ are Medicare claims. The active WHIO Datamart contains 24 months of insurance claims data collected over 27 months for completeness and refreshed approximately every 6 months. ${ }^{6}$
The study population included all patients with an ICD-9 diagnosis code of acute myeloid leukemia or acute lymphoblastic leukemia present in the WHIO database within the 2009-2011 timeframe. Claims costs were categorized and are presented as billed cost, paid cost and standard cost; standard cost is used in these analyses. Finkler previously identified the appropriate use of standard cost for studies with the perspective of actual operational cost or resources used. ${ }^{7}$ WHIO calculates a standard cost variable to adjust for variations related to insurance contracting, region and disease severity and comorbidity, which is expected to provide a closer estimate of actual cost.

\section{Design and Variables}

This study is a cross-sectional secondary analysis of insurance claims data from the WHIO Datamart for patients with acute leukemia. With guidance from the Andersen model, study variables (Table 1) were included based on their expected influence on health care cost at the patient and community level.

Patient county and provider location percentage below poverty variables were calculated using WHIO data combined with U.S. Census data. Six cost criterion variables were analyzed separately: 1) total cost, 2) ancillary cost, 3) inpatient cost, 4) outpatient cost, 5) pharmacy cost, and 6) professional cost. Data were not consistently available for each cost criterion; therefore, while the total cost data set included all 837 patients, each analysis utilized only the data and corresponding population size available per cost criterion.

\section{Statistical Analyses}

Use of administrative databases in health care cost research is challenging due to the limitations of patient demographics, disruption in coverage, availability of clinical outcomes and censored data. Using prior literature as a guide, a generalized linear model (GLM) fitting gamma-distributed data with log-link technique was selected. Literature comparing GLMs for use in health economic analysis suggests the gamma log-link model as a candidate to provide a good fit for health care cost data, given its tendency for skewness, excess zeros and heavy right tails. ${ }^{8-11}$ The final statistical model was selected after a comprehensive assessment of study data as 
Table 1. Description of Study Variables

\begin{tabular}{|c|c|c|c|}
\hline Variable & Behavioral model type & Measurement or range & WHIO DataMart \\
\hline $\begin{array}{l}\text { Leukemia diagnosis cost: } \\
\text { ICD-9 code } 204 . x x \\
\text { ICD-9 code } 205 . x x\end{array}$ & Criterion variable & $\begin{array}{l}\text { Total } \\
\text { Inpatient } \\
\text { Outpatient } \\
\text { Pharmaceutical } \\
\text { Ancillary } \\
\text { Professional }\end{array}$ & $\begin{array}{l}\text { Cost }=\text { billed } \\
\text { Cost }=\text { standard } \\
\text { Service type: } \\
\text { Ancillary }=1 \\
\text { Inpatient }=2 \\
\text { Outpatient }=3 \\
\text { Professional }=4 \\
\text { Pharmacy }=7 \text { (does not } \\
\text { include retail pharmacy claims) }\end{array}$ \\
\hline Age & $\begin{array}{l}\text { Predisposing } \\
\text { characteristic }\end{array}$ & $1-90$ years & Age \\
\hline Gender & $\begin{array}{l}\text { Predisposing } \\
\text { characteristic }\end{array}$ & $\begin{array}{l}0=\text { male } \\
1=\text { female }\end{array}$ & Gender \\
\hline Length of follow-up & $\begin{array}{l}\text { Predisposing } \\
\text { characteristic }\end{array}$ & $1-25$ months & $\begin{array}{l}\text { End date of service to start date } \\
\text { of service }\end{array}$ \\
\hline Episode severity level & Need characteristic & $\begin{array}{l}1=\text { low } \\
2=\text { low } / \text { medium } \\
3=\text { high } / \text { medium } \\
4=\text { high }\end{array}$ & $\begin{array}{l}\text { Severity = highest level of } \\
\text { severity coded }\end{array}$ \\
\hline Treatment type & Need characteristic & $\begin{array}{l}0=\text { chemotherapy only } \\
1=\text { chemotherapy and } \mathrm{HCT}\end{array}$ & ICD code \\
\hline $\begin{array}{l}\text { Patient ZIP code; \% of } \\
\text { county below poverty level }\end{array}$ & Enabling resources & $\begin{array}{l}\text { ZIP: 5-digit character; County } \\
\text { poverty: continuous ratio }\end{array}$ & $\begin{array}{l}\text { ZIP code; U.S. Census for } \% \\
\text { of all people below poverty level }\end{array}$ \\
\hline Payer type & Enabling resources & $\begin{array}{l}0=\text { commercial } \\
1=\text { public }\end{array}$ & $\begin{array}{l}\text { Payer type = public payer coded } \\
\text { when present }\end{array}$ \\
\hline Provider type & Enabling resources & $\begin{array}{l}0=\text { community } \\
1=\text { academic }\end{array}$ & Provider name \\
\hline $\begin{array}{l}\text { Provider ZIP code; \% of } \\
\text { ZIP below poverty level }\end{array}$ & Enabling resources & $\begin{array}{l}\text { ZIP: } 5 \text { digit character; } \\
\text { Provider ZIP poverty: \% }\end{array}$ & $\begin{array}{l}\text { ZIP code; U.S. Census for \% } \\
\text { of all people below poverty level }\end{array}$ \\
\hline
\end{tabular}

HCT, hematopoietic stem cell transplant.

well as for its ability to accommodate right-skewed data, the presence of zeros, differences in follow-up, many low-cost events versus few high-cost events, and overall fit considering model assumptions. The modified Park's test identified both Poisson and gamma family distributions as appropriate, given the cost criterion assessed, and visual inspection of residuals associated with raw and log-transformed data supported use of the log-link for approximating a normal distribution.

Modeling techniques used in this study ultimately produced estimates of predictor variable effect size $\left(e^{\beta}\right)$, quantifying the magnitude of change in mean criterion value per 1-unit change in the predictor variable and offering the advantage of easier comparison and interpretation of differences between groups. ${ }^{12-14}$ Each cost criterion variable was modeled to determine: 1) if a patient's predisposing characteristics (i.e. age, gender and length of followup), need for service factors (i.e. treatment type and episode severity), and enabling patient and community resources (i.e. percentage of residents in patient's county in poverty, payer type, provider type and percentage of residents in provider location in poverty) were predictive of cost; and 2) the magnitude 
of predictor variable influence on cost criterion variables. To identify variables that significantly influenced cost, each cost criterion was initially analyzed in a full model using all study variables. Table 2 provides the description of the final GLM gamma log-link models.

Variables for analysis in reduced models were identified in the GLM using a chi-squared test of the likelihood ratio with $\alpha$ of 0.05 . Finally, a two-step hierarchical model was used to assess the influence of patient and community enabling variables over and above the influence of a patient's predisposing characteristics and need for services. This model began with the predisposing and need variables, then added the patient and community enabling variables.

\section{RESULTS}

Descriptive information of standard cost for each criterion variable is shown in Table 3. Mean standard cost varies greatly between criterion variables, for which inpatient costs were highest and ancillary costs lowest. Large differences were noted between mean and median cost, however, both follow similar direction.

Each significant full-model predictor variable also was significant in the reduced model. Only total cost was analyzed in the hierarchical model, and the results were the same as those of the reduced model. Reduced model results are presented as mean ratios and used a coefficient of variation, which represents the ratio of differences between groups as $\mathrm{e}^{\beta}$ (Table 4).

Table 2. Final GLM Gamma Log-Link Models

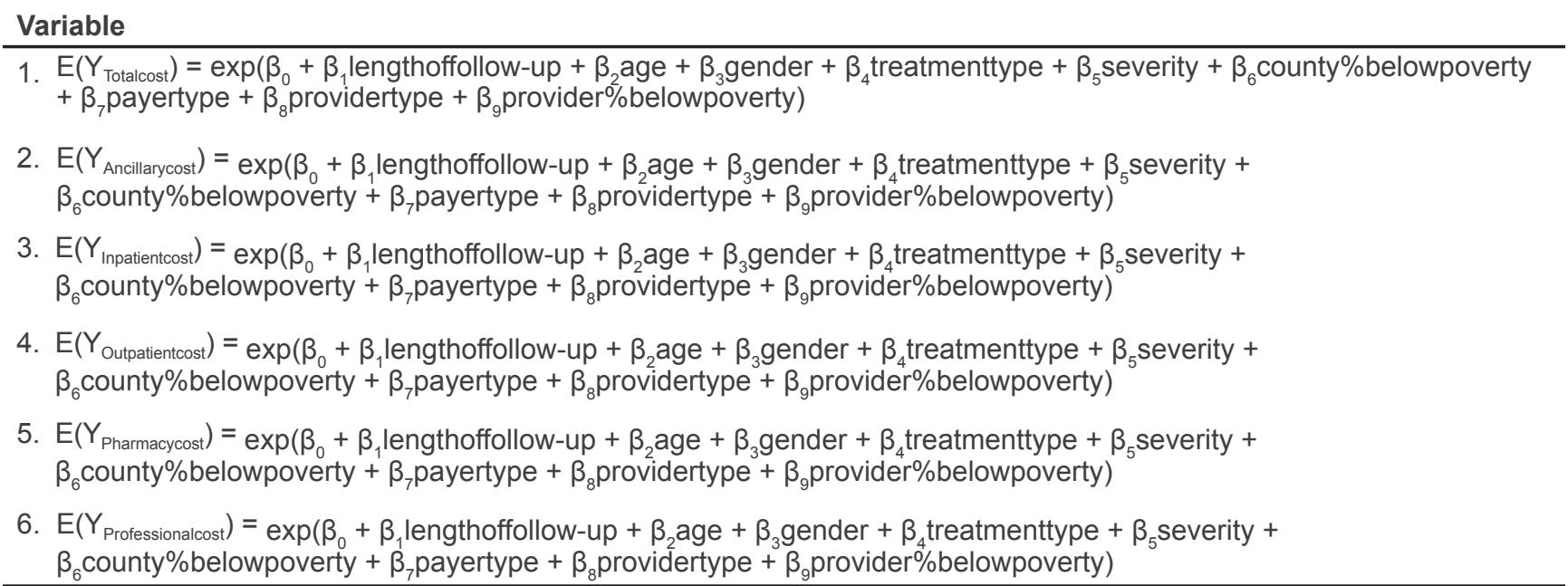

Table 3. Description of Standard Costs

\begin{tabular}{lccccccc}
\hline Cost criterion & N & Mean & Median & $\begin{array}{c}\text { Standard } \\
\text { deviation }\end{array}$ & Range & $\begin{array}{c}\mathbf{2 5 \%} \% \\
\text { quartile }\end{array}$ & $\begin{array}{c}\mathbf{7 5} \% \\
\text { quartile }\end{array}$ \\
\hline Total cost & 837 & 43,379 & 2,723 & 102,703 & $10-1,228,960$ & 539 & 35,471 \\
Ancillary & 164 & 4,123 & 1,230 & 8,834 & $5-64,248$ & 296 & 3,248 \\
Inpatient & 232 & 80,787 & 40,908 & 104,001 & $2,680-836,656$ & 16,855 & 107,750 \\
Outpatient & 639 & 8,410 & 1,953 & 17,590 & $10-227,957$ & 493 & 9208 \\
Pharmacy & 390 & 17,078 & 5,070 & 60,012 & $1-1,097,437$ & 483 & 17,434 \\
Professional & 748 & 6,491 & 1,002 & 11,379 & $7-80,867$ & 298 & 7,448 \\
\hline
\end{tabular}


Table 4. Estimated Reduced Model Summary Results for Standard Cost

\begin{tabular}{|c|c|c|c|c|c|c|}
\hline \multirow{2}{*}{$\begin{array}{l}\text { Predisposing } \\
\text { characteristics* }\end{array}$} & \multicolumn{6}{|c|}{ Reduced model standard claims cost } \\
\hline & Total & Ancillary & Inpatient & Outpatient & Pharmacy & Professional \\
\hline \multicolumn{7}{|l|}{ Age (decade) } \\
\hline $\mathrm{e}^{\beta}$ & 0.92 & 0.98 & 0.88 & 0.92 & 1.15 & 0.88 \\
\hline $95 \% \mathrm{Cl}$ & $0.87-0.96$ & $0.97-1.002$ & $0.83-0.93$ & $0.88-0.97$ & $1.07-1.23$ & $0.84-0.91$ \\
\hline$P$-value & 0.007 & 0.08 & $<0.0001$ & 0.002 & $<0.0001$ & $<0.0001$ \\
\hline \multicolumn{7}{|l|}{ Gender } \\
\hline$e^{\beta}$ & 1.66 & & & 1.3 & & \\
\hline $95 \% \mathrm{Cl}$ & $1.28-2.15$ & & & $1.04-1.64$ & & \\
\hline$P$-value & 0.0001 & & & 0.02 & & \\
\hline \multicolumn{7}{|l|}{$\begin{array}{l}\text { Length of follow-up } \\
\text { (months) }\end{array}$} \\
\hline$e^{\beta}$ & 1.03 & & 0.98 & 1.06 & 1.03 & 1.08 \\
\hline $95 \% \mathrm{Cl}$ & $1.003-1.05$ & & $0.96-1$ & $1.04-1.07$ & $1.05-0.03$ & $1.07-1.09$ \\
\hline$P$-value & $<0.0001$ & & 0.05 & $<0.0001$ & 0.02 & $<0.0001$ \\
\hline \multicolumn{7}{|l|}{$\begin{array}{l}\text { Need } \\
\text { characteristics* }\end{array}$} \\
\hline \multicolumn{7}{|l|}{ Treatment type } \\
\hline$e^{\beta}$ & 0.14 & & 0.3 & 0.19 & & 0.22 \\
\hline $95 \% \mathrm{Cl}$ & $0.06-0.26$ & & $0.2-0.45$ & $0.12-0.32$ & & $0.12-0.36$ \\
\hline$P$-value & $<0.0001$ & & $<0.0001$ & $<0.0001$ & & $<0.0001$ \\
\hline \multicolumn{7}{|l|}{ Severity level 1} \\
\hline$e^{\beta}$ & 0.41 & 0.24 & 0.28 & 0.32 & 0.34 & 0.47 \\
\hline $95 \% \mathrm{Cl}$ & $0.26-0.61$ & $0.07-0.95$ & $0.17-0.49$ & $0.20-0.51$ & $0.17-0.67$ & $0.34-0.67$ \\
\hline$P$-value & 0.0002 & 0.02 & $<0.0001$ & $<0.0001$ & 0.002 & $<0.0001$ \\
\hline \multicolumn{7}{|l|}{ Severity level 2} \\
\hline$e^{\beta}$ & 0.45 & 0.35 & 0.55 & 0.47 & 0.6 & 0.51 \\
\hline $95 \% \mathrm{Cl}$ & $0.34-0.61$ & $0.19-0.66$ & $0.41-0.74$ & $0.34-0.66$ & $0.39-0.93$ & $0.41-0.63$ \\
\hline$P$-value & $<0.0001$ & 0.001 & $<0.0001$ & $<0.0001$ & 0.02 & $<0.0001$ \\
\hline \multicolumn{7}{|l|}{ Severity level 3} \\
\hline$e^{\beta}$ & & 0.32 & & 0.64 & 0.59 & \\
\hline $95 \% \mathrm{Cl}$ & & $0.17-0.61$ & & $0.44-0.92$ & $0.35-0.96$ & \\
\hline$P$-value & & 0.0004 & & 0.02 & 0.03 & \\
\hline $\begin{array}{l}\text { Enabling } \\
\text { resources* }\end{array}$ & Total & Ancillary & Inpatient & Outpatient & Pharmacy & Professional \\
\hline \multicolumn{7}{|l|}{ Provider type } \\
\hline$e^{\beta}$ & 0.71 & 0.46 & 0.73 & 0.56 & 0.62 & \\
\hline $95 \% \mathrm{Cl}$ & $0.54-0.94$ & $0.26-0.79$ & $0.55-0.95$ & $0.43-0.71$ & $0.44-0.89$ & \\
\hline$P$-value & 0.018 & 0.005 & 0.02 & $<0.0001$ & 0.01 & \\
\hline \multicolumn{7}{|l|}{$\begin{array}{l}\text { Provider \% under } \\
\text { poverty }\end{array}$} \\
\hline$e^{\beta}$ & & & & 0.97 & 0.95 & \\
\hline $95 \% \mathrm{Cl}$ & & & & $0.96-0.99$ & $0.93-0.98$ & \\
\hline$P$-value & & & & $<0.0001$ & 0.002 & \\
\hline
\end{tabular}

*Determinants in Andersen's model of health care utilization.

$\mathrm{Cl}$, confidence interval; $\mathrm{e}^{\beta}$, estimates of predictor variable effect size. 


\section{Total Cost}

The average total cost for males was more than one and a half times the average total cost for females, and each additional month that a patient had claims present increased the average total cost by close to $2 \%$. The average total cost of patients treated with only chemotherapy was $86 \%$ lower than the average total cost with both chemotherapy and HCT treatment. Patients with low illness severity (level 1) had a 59\% lower average total cost than higher severity levels; patients with low- to mid-range severity (level 2) had a 55\% less average total cost than higher levels of severity (3 and 4). Community provider's average total costs were $29 \%$ lower than average total costs of academic providers, and patients average total cost was $8 \%$ lower for every 10 -year increase in patient age.

\section{Ancillary Cost}

The average ancillary cost of patients with low illness severity (level 1) was $76 \%$ lower than the average ancillary cost of patients with high severity level 4, patients with mid-range severity levels (levels 2 and 3) had $66 \%$ and $68 \%$ lower average ancillary costs than patients with high severity (level 4). Community provider average ancillary costs were $54 \%$ lower than the average ancillary cost of academic providers.

\section{Inpatient Cost}

The average inpatient cost of patients treated with only chemotherapy was $70 \%$ lower than the average inpatient cost of both chemotherapy and HCT treatment. Patients with low illness severity (level 1) had a $72 \%$ lower average inpatient cost than patients with high severity (level 4), and patients with mid-range severity (level 2) had a $45 \%$ lower average inpatient standard cost than those with high severity (level 4). Community providers had 27\% lower average inpatient cost than academic providers. Average inpatient cost was reduced by $12 \%$ for every 10-year increase in patient age, and each additional month that a patient had claims increased the average inpatient cost by close to $2 \%$.

\section{Outpatient Cost}

Males had 30\% higher average outpatient cost compared to females, and each additional month that claims were present increased average outpatient cost by $5.5 \%$. For each 10-year increase in age, average outpatient cost decreased by $7.6 \%$. Patients treated with only chemotherapy had an $81 \%$ lower average outpatient cost than patients treated with both chemotherapy and HCT. Patients with low illness severity (level 1) had a 68\% lower average outpatient cost than patients with high severity (level 4), patients with mid-range severity (level 2 or 3 ) had a $53 \%$ and $36 \%$ lower average outpatient cost, respectively, than those with high severity (level 4). Community providers had a $44 \%$ lower average outpatient cost than academic providers, and every $1 \%$ increase in the rate of poverty at the provider's location reduced average outpatient cost by $3 \%$.

\section{Pharmacy Cost}

For each 10-year increase in patient age, average pharmacy cost decreased by $15 \%$. Each additional month that claims were present increased average pharmacy cost by 3\%. Patients with low illness severity (level 1) had a 66\% lower average pharmacy cost than patients with high severity (level 4); patients with mid-range severity (level 2 or 3 ) had a $40 \%$ and $41 \%$ lower average pharmacy cost, respectively, than those with high severity (level 4). Cost for community providers was $38 \%$ lower than the average pharmacy cost of an academic provider, and every $1 \%$ increase in the provider location poverty rate reduced average pharmacy cost by $5 \%$.

\section{Professional Cost}

Each additional month that a patient had claims present increased average professional cost by close to $8 \%$. For each 10 -year increase in age, average professional cost decreased by $12.5 \%$. Patients treated with only chemotherapy had a 78\% lower average professional cost than those treated with both chemotherapy and HCT. Patients with low illness severity (level 1) had a 53\% lower average professional cost than patients with high severity (level 4), and patients with mid-range severity (level 2) had a $49 \%$ lower average professional cost than high-severity patients (level 4).

\section{DISCUSSION}

The objective of this study was to identify and better understand factors associated with use of health services specific to patients diagnosed with acute myeloid leukemia and acute lymphoblastic leukemia. The overall health care cost burden of a patient is 
determined by the type of service received, where it was received, who provided it and its duration. This study investigated ancillary, inpatient, outpatient, pharmacy and professional costs in addition to total cost in an attempt to distinguish how the cost of each type of service impacts the total cost to the patient. Acute leukemia patient characteristics of the study population were consistent with those reported nationally. ${ }^{15}$ Patient characteristics were consistent between each criterion, with a mean age of either 27 or 28 and a higher percentage of males, as would be expected from the higher rate of leukemia diagnoses in males. Such demographics are similar to national Surveillance, Epidemiology, and End Results (SEER) statistics, which report a higher percentage of men with acute leukemia diagnoses as well as both a younger acute lymphoblastic leukemia population and an older acute myeloid leukemia population. ${ }^{15}$

Our study found certain patient characteristics to be predictive of cost; however, it also revealed that health care costs of rare disease populations may not follow cost patterns for more common disease. Prior research identifies increasing age as a factor associated with higher health care utilization rates and costs. ${ }^{16}$ This study found that the younger age of an acute leukemia patient is associated significantly with higher average cost. Bertakis et al. identified a gender difference in the use of health care services, with a higher rate of use in women. ${ }^{17}$ However, in this study population, men had higher costs. Billings et al. found higher rates of hospitalization in low-income areas attributed to less timely and effective outpatient care. ${ }^{18}$ For certain cost variables in our study the opposite was found, in that inpatient cost was lower in low-income areas.

Other study results were consistent with more typical health care cost patterns. Zweifel et al. reported cost of treatment to be an important driver of total cost, ${ }^{19}$ similar to our study's findings. Patients receiving treatment with HCT experienced significantly higher cost when compared to those treated only with chemotherapy. This finding is consistent with the identification of HCT as the procedure with the most rapidly increasing cost between 2004 and 2007. ${ }^{20}$ Advances in scientific knowledge have expanded HCT treatment to a variety of hematologic diseases and disorders; however, its high cost makes it vulnerable to cost containment. As expected, patients with higher severity of illness had higher cost associated with an increased need for health care services. In the Andersen model, socioeconomics is considered a factor that may impact how patients use health care services, with higher socioeconomic status supporting higher utilization. ${ }^{5}$ Findings of this study support the theory of lower costs associated with lower utilization and lower socioeconomic status. Finally, the direction of study findings were not consistent between the different types of services received and underscore the complexity of understanding the factors that drive the total cost outcome.

\section{Study Limitations}

The study's research design was restricted because of the limitations of data available in the WHIO administrative claims database. Data censoring due to death and changes in patient insurance influence the amount of follow-up claims data available, and such causes were not delineated in the database. The study population was defined by a subset of Wisconsin insurance claims and did not include patients who did not pay with insurance or used insurance administered from a different U.S. state. Patient ZIP code was available at the county level only, and its specificity was reduced. Assessment of interactions was outside the scope of the analysis due to the number of potential combinations. Finally, analysis of cost data was complex due to its tendency to be skewed, with long, right tails, multiple zero values and large differences in rates of health services utilization causing a higher proportion of heath care cost to be attributed to a smaller group of patients, and a non-normal distribution of data.

\section{CONCLUSIONS}

Health care costs of less common diseases such as acute leukemia may not follow patient characteristic patterns found in more common disease populations. Using Andersen's behavioral model of health care utilization, study variables were identified that represent patient and community factors expected to influence cost. Based on a generalized linear model fitting gamma-distributed data with log-link technique, individual and community factors were found to be significant predictors within each cost criterion and 
provide opportunities for further investigation of higher costs at the patient, provider and community levels. Assessing the unique influence of each variable on each cost outcome as well as further exploration into types of treatment offered by providers in different socioeconomic locations is advisable.

\section{Patient-Friendly Recap}

- Health care costs for patients with leukemia are substantial.

- The authors reviewed statewide data to determine which patient, provider and community factors drive up total cost.

- They found that type of treatment received and disease severity were the biggest contributors to higher cost, but also observed a jump in patients receiving at least some of their treatment from an academic medical center.

- Inpatient and pharmacy costs were lower when providers were located in impoverished areas, raising the possibility of treatment disparities.

\section{Acknowledgments}

The authors thank Dan Eastwood, Medical College of Wisconsin, Division of Biostatistics, for his support with development and interpretation of the statistical methods.

\section{Conflicts of Interest}

None.

\section{Funding Sources}

Funding for data was provided by the Center for Urban Population Health. Dr. Steinert is currently employed by the Center for International Blood and Marrow Research at the Medical College of Wisconsin; she conducted this study as a doctoral dissertator in the College of Health Sciences at the University of Wisconsin-Milwaukee and the Center for Urban Population Health under the guidance of Dr. Cisler.

\section{References}

1. U.S. Department of Health and Human Services. 2011 report to Congress: national strategy for quality improvement in health care (March 2011). http://www.ahrq.gov/workingforquality/ nqs/nqs2011 annlrpt.htm. Accessed May 23, 2016.
2. Yu YB, Gau JP, You JY, et al. Cost-effectiveness of postremission intensive therapy in patients with acute leukemia. Ann Oncol. 2007;18:529-34. CrossRef

3. Aday LA. Establishment of a conceptual base for health services research. J Health Serv Res Policy. 2001;6:183-5. CrossRef

4. Andersen RM. A behavioral model of families' use of health services. Research Series No. 25. Chicago, IL: Center for Health Administration Studies, University of Chicago, 1968.

5. Andersen RM. Revisiting the behavioral model and access to medical care: does it matter? J Health Soc Behav. 1995;36: 1-10. CrossRef

6. Wisconsin Health Information Organization. WHIO Health Datamart stats. http://www.wisconsinhealthinfo.org/. Accessed May 23, 2016.

7. Finkler SA. The distinction between cost and charges. Ann Intern Med. 1982;96:102-9. CrossRef

8. Dodd S, Bassi A, Bodger, Williamson P. A comparison of multivariable regression models to analyze cost data. J Eval Clin Pract. 2006;12:76-86. CrossRef

9. Barber J, Thompson S. Multiple regression of cost data: use of generalised linear models. J Health Serv Res Policy. 2004;9:197-204. CrossRef

10. Basu A, Manning WG. Issues for the next generation of health care cost analyses. Med Care. 2009;47(7 suppl 1):S109-14. CrossRef

11. Lin DY. Linear regression analysis of censored medical costs. Biostatistics. 2000;1:35-47. CrossRef

12. Neal DJ, Simons JS. Inference in regression models of heavily skewed alcohol use data: a comparison of ordinary least squares, generalized linear models, and bootstrap resampling. Psychol Addict Behav. 2007;21:441-52. CrossRef

13. Manning WG, Mullahy J. Estimating log models: to transform or not to transform? J Health Econ. 2001;20:461-94. CrossRef

14. Basu A. Extended generalized linear models: simultaneous estimation of flexible link and variance functions. The Stata Journal. 2005;5:501-16.

15. National Cancer Institute. Surveillance, epidemiology, and end results program. http://seer.cancer.gov. Accessed May 23, 2016.

16. Seshamani M, Gray A. Ageing and health-care expenditure: the red herring argument revisited. Health Econ. 2004;13: 303-14. CrossRef

17. Bertakis KD, Azari R, Helms LJ, Callahan EJ, Robbins JA. Gender differences in the utilization of health care services. J Fam Pract. 2000;49:147-52.

18. Billings J, Zeitel L, Lukomnik J, Carey TS, Blank AE, Newman L. Impact of socioeconomic status on hospital use in New York City. Health Aff (Millwood). 1993;12:162-73. CrossRef

19. Zweifel P, Felder S, Werblow A. Population ageing and health care expenditure: new evidence on the "red herring." The Geneva Papers on Risk and Insurance. 2004;29:652-66.

20. Stranges E, Russo A, Friedman B. Procedures with the most rapidly increasing hospital costs, 2004-2007: statistical brief \#82 (http://www.hcup-us.ahrq.gov/reports/statbriefs/sb82. pdf). Healthcare Cost and Utilization Project Statistical Briefs. Rockville, MD: Agency for Healthcare Research and Quality, Rockville, MD, 2009 (December).

(C) 2016 Aurora Health Care, Inc. 